\title{
Party cues no Brasil? Um teste crucial da capacidade do sistema de partidos brasileiro em influenciar a opinião pública
}

\author{
Wladimir Gramacho ${ }^{1}$ (D)
}

\begin{abstract}
Este artigo apresenta um teste crucial da teoria das pistas partidárias (party cues) ao investigar a associação entre as posições legislativas do sistema de partidos políticos brasileiro, numa dimensão governo-oposição, e a avaliação governamental feita por seus simpatizantes. O contexto do teste é o governo Fernando Henrique Cardoso (1995-2002), marcado por sucessivas crises econômicas, o que tenderia a reduzir o poder de influência dos partidos sobre a opinião pública, frente ao tradicional poder explicativo das teorias do voto econômico e das funções de popularidade. Os resultados, baseados em modelos multiníveis a partir da análise de sete surveys, sugerem que as pistas partidárias funcionam inclusive num país como o Brasil e no contexto adverso escolhido nesse teste empírico. Os achados indicam ainda que as pistas partidárias são mais fortes segundo a relevância midiática de cada partido.
\end{abstract}

Palavras-chave: pistas partidárias; aprovação governamental; mídia; voto econômico; funções de popularidade; análise multinível

\section{Introdução}

Este artigo apresenta um teste crucial da capacidade dos partidos políticos de influenciar as opiniões de seus simpatizantes, prevista pela teoria das pistas partidárias ou party cues (Ray, 2003; Edwards et al., 2005; Petersen et al., 2012; Dancey e Sheagley, 2013; Nicholson e Hansford, 2014; Bisgaard e Slothuus, 2018). Seguindo Eckstein (1975) e Rueschemeyer (2003), um teste crucial é determinado pela escolha de um least likely case, ou seja, um caso em que é menos provável a rejeição da hipótese nula. Se nesse cenário adverso a hipótese nula fosse rejeitada, ela também tenderia a sê-lo em contextos mais favoráveis. Em outras palavras, se os partidos políticos são capazes de influenciar as

\footnotetext{
1 Universidade de Brasília, Faculdade de Comunicação. Brasília (DF), Brasil. E-mail: <wggramacho@unb.br>. 2 Agradeço às/aos pareceristas da revista pelas valiosas contribuições que aperfeiçoaram este artigo, assim como a outros colegas, como José Ramón Montero, Clara Riba, Timothy J. Power, Araceli Mateos Díaz, Alessandro Freire e Pedro Mundim, que revisaram e comentaram versões anteriores deste artigo, e Álvaro Pereira e Victor Gomes, que auxiliaram na elaboração de figuras e na revisão do texto. Sou grato, em especial, a Iván Llamazares por suas sugestões originais e críticas elegantes na elaboração do desenho da pesquisa. Erros e inconsistências remanescentes, entretanto, são de minha inteira responsabilidade.
} 
opiniões de seus apoiadores no Brasil - país em que as agremiações são especialmente débeis em seus laços com eleitores -, eles provavelmente o farão em quaisquer outras democracias nas quais esses vínculos sejam mais robustos.

O sistema político brasileiro tem sido tradicionalmente caracterizado pela fragilidade da conexão eleitoral de seus partidos e seu baixo enraizamento social, em comparação com outras democracias, inclusive da América Latina (Mainwaring, 1995; Pereira e Müeller, 2003). Ainda que alguns autores tenham reconhecido a força institucional e a capacidade governativa dos partidos políticos brasileiros (Nicolau, 2000; Amorim Neto, Cox e McCubbins, 2003; Braga, 2010; Melo e Câmara, 2012), tem sido dominante na ciência política a descrição da incapacidade dessas organizações em estabelecer vínculos próximos, duradouros e influentes com parcelas expressivas da população (Carreirão, 2007a; Paiva e Tarouco, 2011; Borges e Vidigal, 2018). O Partido dos Trabalhadores (PT) tem sido apontado como a exceção a esse diagnóstico, tanto por sustentar desde 1999 a liderança de preferência partidária no país (Carreirão e Kinzo, 2004; Paiva e Tarouco, 2011) como por ser objeto de uma antipatia partidária que orienta posicionamentos e votos contra candidatos da legenda (Ribeiro, Carreirão e Borba, 2016; Samuels e Zucco Junior, 2018). Entretanto, pouco ainda se sabe sobre a capacidade agregada do sistema de partidos brasileiro em influenciar as opiniões individuais no país.

Entre as explicações possíveis para esse reduzido enraizamento social, estão: os incentivos do presidencialismo ao surgimento de outsiders (Linz, 1994; O’Donnell, 1992); uma organização federativa que pode estimular a fragmentação e inibir a efetiva nacionalização de legendas (Chhibber e Kollman, 2004; Jones e Mainwaring, 2003; Borges, 2015); um sistema eleitoral "centrado no candidato", em que os postulantes ao Legislativo têm mais incentivos para pedir votos para si mesmos que para seus partidos (Samuels, 1997); regras flexíveis de fidelidade partidária (Melo, 2000, 2004); e uma história política com marcada experiência populista (Weffort, 1989; Masiero, 1991; Roberts, 1998; Weyland, 2003).

Uma primeira prova crucial da teoria das pistas partidárias no Brasil pode ser encontrada no estudo pioneiro de Samuels e Zucco Junior (2014), realizado em 2010 e 2011, que obteve resultados favoráveis à hipótese de que os partidos políticos brasileiros têm influência sobre a opinião de seus seguidores. Com base em dois experimentos inseridos em surveys, os autores mostraram que as opiniões de simpatizantes do PT e do PSDB sobre diversos temas (e.g., salário mínimo, pré-sal e adesão da Venezuela ao Mercosul) oscilavam de acordo com a presença de pistas partidárias. Isto é, um simpatizante do PT [PSDB] declarava maior concordância com afirmações apoiadas pelo PT [PSDB] do que afirmações sem nenhum apoio, e tendia a concordar menos com essa mesma afirmação quando o apoio estava associado ao PSDB [PT]. Esse achado, portanto, mostra que as pistas podem ter um efeito in-group, quando provenientes do partido pelo qual o(a) eleitor(a) tem simpatia, ou um efeito out-group, quando advindas de um partido pelo qual tem antipatia. 
Este artigo pretende ampliar o teste empírico sobre a existência de pistas partidárias no Brasil introduzindo três inovações importantes em comparação com o desenho de pesquisa de Samuels e Zucco Junior (2014). Em primeiro lugar, busca-se analisar a associação entre as posições não apenas do PT e do PSDB e de seus respectivos simpatizantes, mas também do sistema de partidos brasileiro e de seus adeptos. Mais especificamente, consideram-se os nove partidos com maior número de simpatizantes entre 1995 e 2002, segundo os surveys analisados. Ou seja, amplia-se de modo importante o escopo dessa influência para além dos partidos que foram centrais na disputa de eleições presidenciais no país entre 1989 e 2014.

Em segundo lugar, optou-se por avaliar a influência dos partidos sobre um easy issue, isto é, um tema sobre o qual os indivíduos em geral têm facilidade em formar uma opinião (Joslyn e Haider-Markel, 2002), e não sobre hard issues (e.g., questões fiscais, de infraestrutura ou de política externa), como os analisados por Samuels e Zucco Junior (2014), em que é mais custoso em termos cognitivos e informacionais formar uma opinião. Nesse caso, pretende-se analisar a influência do sistema de partidos sobre o desempenho do governo federal com base em sete surveys conduzidos pelo Instituto Datafolha de 1995 a 2002. Afinal, hard issues exigem maior conhecimento técnico e soem estimular os indivíduos a se apoiar - de fato - em influenciadores, sejam especialistas ou partidos políticos. Já a avaliação do desempenho governamental pode ser formulada a partir de várias fontes de informação e experiências cotidianas dos indivíduos, que serão discutidas ainda nesta introdução.

Em terceiro e último lugar, este desenho de pesquisa optou por analisar dados de um contexto político-econômico adverso à identificação de apoio empírico à teoria das pistas partidárias. Isto é, escolheu-se analisar uma conjuntura na qual a avaliação do desempenho do governo federal deveria responder muito mais a fatores não associados ao vínculo partidário do que a essa conexão política. Mais especificamente, a análise aqui realizada observa a associação entre a posição do sistema de partidos na dimensão governo-oposição e as opiniões de seus simpatizantes sobre o desempenho do governo do ex-presidente Fernando Henrique Cardoso (1995-2002).

Como se sabe, o Plano Real e sua repercussão econômica são vistos como a dimensão mais importante da popularidade de FHC desde sua eleição em 1994 (Meneguello, 1996; Gramacho, 2005), e sua gestão foi marcada por reformas regulatórias e sucessivas tentativas de estabilizar a economia, que manteve grande saliência midiática durante os oitos anos de seus dois mandatos. Além disso, a então recente reinauguração da vida democrática no país havia oferecido poucas oportunidades de conexão entre os partidos e seus eleitores; e o contexto tecnológico prescindia de redes sociais e outros meios digitais que permitissem aos políticos estabelecer uma comunicação mais direta com os indivíduos.

Sob a perspectiva teórica, ademais, a investigação da influência de pistas partidárias sobre a popularidade governamental coloca os partidos "em competição" com 
um tradicional e potente determinante da aprovação dos governos: o desempenho da economia (Lewis-Beck e Stegmaier, 2013; Lewis-Beck et al., 2013; Nadeau et al., 2012; Lewis-Beck, 1990; Maravall e Przeworski, 2001; Carreirão, 1999; Rennó e Spanakos, 2006; Rennó e Gramacho, 2010; Mundim, Gramacho e Pinto, 2018). No contexto do governo FHC, portanto, seria ainda mais esperável que sua popularidade respondesse muito mais ao comportamento dos principais indicadores econômicos e dos juízos subjetivos dos indivíduos sobre a economia do que ao posicionamento de partidos políticos tradicionalmente vistos como débeis.

O escopo metodológico deste artigo está orientado a analisar as seguintes perguntas de pesquisa: As posições do sistema de partidos políticos brasileiro sobre um easy issue, como a avaliação do governo federal, estão associadas às opiniões de seus simpatizantes? Essa associação pode ser observada especialmente num contexto em que outros fatores (i.e., a economia) facilmente bastariam para a formação de opiniões? Se essa associação existe, ela é igual para todos os partidos? Ou partidos com maior relevância midiática têm maior influência?

Os resultados apresentados ao longo do texto revelam que as posições do sistema de partidos na dimensão governo-oposição estiveram, sim, associadas às opiniões de seus simpatizantes sobre o desempenho do governo FHC. Além disso, partidos com maior relevância midiática parecem ter exercido maior influência sobre as opiniões de seus simpatizantes. Em síntese, os resultados apoiam a teoria das pistas partidárias, mesmo em condições adversas, como em um país em que os partidos têm reduzida institucionalização e enraizamento social como o Brasil, em um contexto de sucessivas crises econômicas, como o da administração $\mathrm{FHC}$, e em um tema de fácil formação de opinião, como a avaliação do governo federal.

O argumento deste artigo está organizado em cinco seções adicionais. A primeira faz uma revisão sucinta da literatura sobre pistas partidárias com o propósito específico de indicar a origem das hipóteses de trabalho desta pesquisa. Foge ao escopo deste artigo, assim, uma revisão mais ampla e exaustiva da teoria das pistas partidárias. A segunda seção descreve os dados utilizados e o contexto político-econômico do governo FHC. A terceira apresenta os modelos de análise multinível aplicados neste estudo e discute seus resultados. A quarta indica as limitações deste artigo e, finalmente, a quinta e última seção reúne as conclusões do artigo e sugere possíveis tópicos para pesquisas futuras.

\section{A teoria das pistas partidárias}

A teoria das pistas partidárias, também conhecida como cue-taking, considera que os indivíduos raciocinam a partir de baixos níveis informacionais (low-information rationality) e usam os partidos políticos como um de seus principais atalhos cognitivos para compreender seu entorno e manifestar percepções e preferências (Popkin, 1991; Sniderman, 1993; Carrubba, 2001; Ray, 2003; Edwards et al., 2005; Petersen et al., 2012; 
Dancey e Sheagley, 2013; Nicholson e Hansford, 2014; Bisgaard e Slothuus, 2018), ainda que existam exceções a essa expectativa (Boudreau e Mackenzie, 2014; Mérola e Hitt, 2016). Uma pista partidária pode ser definida como qualquer mensagem ou voto emitido por representante de um partido político que permita a seu simpatizante formar opinião ou decidir sobre um assunto.

Se, por um lado, obter informações e processá-las impõe custos (Downs, 1957), por outro, a heurística permite reduzir o valor desse investimento e, ainda assim, manter níveis razoáveis de compreensão sobre a política (Popkin, 1991; Zaller, 1992; Druckman, Peterson e Slothuus, 2013). Em sistemas democráticos, as manifestações e os votos de lideranças constituem uma das principais fontes de atalhos informativos para os indivíduos (Shively, 1979; Campbell et al., 1960), inclusive em condições de risco ou incerteza (Druckman, 2001).

A teoria das pistas partidárias, portanto, considera que os partidos políticos não são irrelevantes para o processo de formação de opiniões e atitudes pelos indivíduos. É verdade que as siglas podem ter perdido importância em diferentes países (Dalton, 2000 e 2004; Dalton e Wattenberg, 2000; Daalder, 2002), dando lugar a novos atores políticos (Lawson e Merkl, 1988; Mancini e Swanson, 1996), mas sua capacidade de adaptação às mudanças tecnológicas e sociais faz com que continuem sendo importantes para o funcionamento da democracia (Aldrich, 1995; Montero e Gunther, 2002; Gunther e Diamond, 2003; Alcántara, 2004).

A hipótese central da teoria das pistas partidárias prevê que as opiniões e os comportamentos dos indivíduos estarão de acordo com a posição dos partidos políticos com que simpatizam, sobretudo nos assuntos sobre os quais seja mais difícil para os indivíduos decidir. Assim, ainda que os indivíduos tenham várias fontes de informação para avaliar o desempenho de uma administração, espera-se que $(\mathrm{H} 1)$ a aprovação do governo entre simpatizantes de algum partido político esteja associada à posição do partido de sua preferência na dimensão governo-oposição. A avaliação dessa hipótese, como argumentado anteriormente, constitui o teste crucial para a teoria das pistas partidárias neste estudo.

A influência esperada, contudo, nem sempre tem efeito uniforme. Há na literatura expectativas de que essa associação básica prevista em $\mathrm{H} 1$ possa ser moderada por variáveis de nível individual (e.g., nível educacional, como em Zaller, 1992; ou Dalton e Wattenberg, 2000), variáveis de nível partidário (e.g., sua disciplina interna ou nível de mobilização das bases, como em Ray, 2003, ou Powell, 2000) ou variáveis de nível conjuntural (e.g., divisão das elites, como em Zaller, 1992, ou Ray, 2003).

No nível partidário, em particular, trabalhos anteriores ainda não se ocuparam do papel que a mídia pode ter como moderadora desses atalhos cognitivos. A influência dos partidos sobre a formação da opinião pública enfrenta restrições que têm sido estabelecidas há mais de um século pelo entorno tecnológico e midiático (Iyengar e Kinder, 1987; Price, 1992; Kaid e Holtz-Bacha, 1995; Mancini e Swanson, 1996; Manin, 1998; 
Dalton, 2000; Norris, 2002; Vreese, 2006, entre outros), desde a imprensa escrita até a comunicação digital, passando pelo período de ouro da hegemonia da TV aberta (Prior, 2007). Para Dalton e Wattenberg (2000), a mídia não só redesenhou o espaço político no qual a competência partidária passa a ter lugar, mas também se transformou no instrumento central de comunicação dos partidos com seus votantes.

Se a comunicação entre partidos e eleitores já não se dá majoritariamente com base em contatos pessoais ou pela imprensa partidária, mas por meio dos veículos de comunicação (e, mais recentemente, pelas mídias digitais), seria esperável que a influência dos partidos sobre a opinião pública já não estivesse relacionada com alguns aspectos organizativos de caráter interpessoal (Ray, 2003), mas sim que fosse determinada por suas características intermediadas, em especial a sua capacidade de se comunicar com seus eleitores e demais indivíduos por meio dos veículos de comunicação (Margolis e Mauser, 1989). Nesse sentido, a segunda hipótese de trabalho deste artigo sustenta que (H2) as pistas partidárias são moderadas pela relevância midiática de cada partido. Isto é, têm maior influência sobre as opiniões de seus simpatizantes os partidos mais proeminentes na mídia. O argumento subjacente a essa hipótese sustenta que partidos cujos posicionamentos e lideranças cativam mais a atenção da mídia geram maiores oportunidades de serem vistos, lidos ou ouvidos por seus simpatizantes.

Os dados disponíveis neste artigo permitem testar, adicionalmente, algumas hipóteses sobre pistas partidárias e popularidade governamental. Entretanto, esses testes são apenas incidentais, no caso das hipóteses $\mathrm{H} 3$ e H4 indicadas a seguir, ou servem como controle, no caso das hipóteses de $\mathrm{H} 5$ a H9. No nível individual, acredita-se que (H3) o efeito das pistas partidárias seja maior entre indivíduos de maior escolaridade, devido à sua maior capacidade de compreender e vincular mensagens dos partidos com os quais simpatizam a opiniões ou decisões que precisam tomar sobre algum tema. Além disso, espera-se que ( $\mathrm{H} 4)$ o efeito das pistas partidárias seja maior entre os indivíduos mais velhos, uma vez que estes costumam ter maior interesse por política e maior informação política que os jovens (Delli Carpini e Keeter, 1996; Elo e Rapeli, 2010). Estariam, portanto, mais sujeitos aos efeitos das pistas partidárias.

Com base na literatura sobre o voto econômico e as funções de popularidade, podese esperar que a aprovação ao governo seja maior (H5) entre indivíduos que tenham uma avaliação positiva do seu programa econômico e que tenham expectativas otimistas com relação (H6) à inflação e (H7) ao desemprego. Além disso, espera-se que a aprovação ao governo seja maior em conjunturas com (H8) menor inflação e (H9) menor desemprego. A Tabela 1 resume as hipóteses do estudo. A próxima seção descreve os dados utilizados e o contexto político-econômico do governo FHC. 
Tabela 1

Descrição das hipóteses do estudo

\begin{tabular}{|l|l|}
\hline Código & \multicolumn{1}{c|}{ Expectativa } \\
\hline H1: Pistas partidárias & $\begin{array}{l}\text { A aprovação do governo pelos indivíduos está associada à posição mais } \\
\text { governista ou mais oposicionista do partido com o qual simpatizam. }\end{array}$ \\
\hline H2: Relevância midiática & $\begin{array}{l}\text { As pistas partidárias são moderadas pela relevância midiática de cada partido. } \\
\text { Isto é, têm maior influência sobre as opiniões de seus simpatizantes os } \\
\text { partidos mais proeminentes na mídia. }\end{array}$ \\
\hline H3: Escolaridade & O efeito das pistas partidárias é maior entre indivíduos de maior escolaridade. \\
\hline H4: Idade & O efeito das pistas partidárias é maior entre os indivíduos mais velhos. \\
\hline $\begin{array}{l}\text { H5: Voto econômico subjetivo } \\
\text { retrospectivo }\end{array}$ & $\begin{array}{l}\text { A aprovação ao governo é maior [menor] entre indivíduos que têm uma } \\
\text { avaliação positiva [negativa] do seu programa econômico. }\end{array}$ \\
\hline $\begin{array}{l}\text { H6: Voto econômico subjetivo } \\
\text { prospectivo (inflação) }\end{array}$ & $\begin{array}{l}\text { A aprovação do governo é maior [menor] entre indivíduos otimistas } \\
\text { [pessimistas] com relação à inflação. }\end{array}$ \\
\hline $\begin{array}{l}\text { H7: Voto econômico subjetivo } \\
\text { prospectivo (desemprego) }\end{array}$ & $\begin{array}{l}\text { A aprovação do governo é maior [menor] entre indivíduos otimistas } \\
\text { [pessimistas] com relação ao desemprego. }\end{array}$ \\
\hline $\begin{array}{l}\text { H8: Voto econômico objetivo } \\
\text { retrospectivo (inflação) }\end{array}$ & $\begin{array}{l}\text { A aprovação do governo é maior [menor] em conjunturas com menor [maior] } \\
\text { inflação. }\end{array}$ \\
\hline $\begin{array}{l}\text { H9: Voto econômico objetivo } \\
\text { retrospectivo (desemprego) }\end{array}$ & $\begin{array}{l}\text { A aprovação do governo é maior [menor] em conjunturas com menor [maior] } \\
\text { desemprego. }\end{array}$ \\
\hline
\end{tabular}

Fonte: Elaboração do autor.

\section{Os dados e o governo FHC}

O banco de dados utilizado neste artigo tem informações e observações de três fontes: surveys conduzidos pelo Instituto Datafolha (1995, 1997-2002), indicadores macroeconômicos produzidos pelo Instituto Brasileiro de Geografia e Estatística (IBGE) e resultados de votações disponíveis no site da Câmara dos Deputados ${ }^{3}$. Esta seção explica e descreve brevemente o comportamento das variáveis que serão analisadas em seguida.

A variável dependente deste estudo é a aprovação ao governo FHC medida numa escala de 0 a 10 pelo Instituto Datafolha em sete surveys ${ }^{4}$ realizados entre os anos de 1995 e $2002^{5}$. Ao todo, foram entrevistados 88.077 brasileiros nessas pesquisas. Neste artigo, entretanto, consideram-se apenas 34.193 dessas observações, após serem descartadas as entrevistas com indivíduos que não preferiam nenhum dos partidos políticos estudados (em média, $41 \%$ a cada survey) ou não respondiam a todas as perguntas de interesse (em média, 20\% a cada survey). A popularidade de FHC em seus mandatos correspondeu ao padrão observado por Carlin et al. (2018), com uma lua de mel, seguida

3 Disponível em: <https://www2.camara.leg.br/atividade-legislativa/plenario/resultadoVotacao>. Acesso em: 15 jun. 2021.

${ }^{4} \mathrm{O}$ universo das pesquisas são os brasileiros com idade igual ou superior a 16 anos. A seleção das amostras usadas pelo instituto está baseada no método de amostragem estratificada, no qual o país é dividido em quatro regiões (Sul, Sudeste, Nordeste e Norte/Centro-Oeste). Em cada região, os municípios são agrupados segundo sua localização e seu nível socioeconômico. Dentro de cada grupo, sortearam-se municípios, bairros, ruas, habitações e indivíduos que responderam às entrevistas.

5 Procurei utilizar surveys ao final de cada ano, mas isso não foi possível para os anos de 1996 (em que os estudos realizados tinham número de entrevistas muito menor que nos demais anos, o que inviabilizaria uma análise de dados dos simpatizantes dos nove partidos) e 2000 (cuja pesquisa mais recente que interrogava os entrevistados sobre seu partido político preferido havia sido produzida em junho). Logo, não foi analisado nenhum survey do ano de 1996, e o survey referente a 2000 não é do mês de dezembro, mas de junho. 
por um declínio (especialmente após a desvalorização do real, em 1999) e uma recuperação ao final do segundo mandato.

Os dados do Datafolha também contemplam seis variáveis de nível individual. Três delas são determinantes tradicionais nos estudos de funções de popularidade. A primeira reporta uma avaliação retrospectiva dos entrevistados sobre o Plano Real, responsável pela estabilização monetária nos anos 1990. As respostas a essa questão foram recodificadas neste estudo e ganharam valor "-1" para os juízos negativos (que consideravam o plano "ruim" ou "péssimo"), valor "0" para respostas neutras ("regular" e "indiferente") e valor "+1" para as opiniões positivas ("ótimo" e "bom"). A dinâmica da avaliação do Plano Real foi muito parecida com a de aprovação do próprio governo, com juízos mais positivos no primeiro mandato, mais negativos em 1999 e em recuperação nos últimos três anos de gestão.

Ademais, outras duas perguntas investigaram a dimensão prospectiva do voto econômico (Nickelsburg e Norpoth, 2000; Dorussen e Palmer, 2002a e 2002b), captando as expectativas dos entrevistados sobre o desempenho futuro da inflação e do desemprego ${ }^{6}$. Essas variáveis também têm valores "-1" (para os pessimistas), "0" (para neutros ou indecisos) e " $+1 "$ (para otimistas). Com relação ao futuro da inflação, os brasileiros estiveram mais otimistas nos dois primeiros anos do governo FHC, pessimistas nos cinco anos seguintes (especialmente em 1999) e novamente otimistas em 2002, neste caso após a vitória eleitoral de Lula. Já com relação ao desemprego, os brasileiros estiveram pessimistas durante todo o período, salvo em dezembro de 2002, provavelmente mais animados com a eleição do candidato oposicionista do PT. Ainda no nível individual, as outras três variáveis eram sociodemográficas: gênero (dummy com valor "1" para as mulheres e "0" para os homens), idade (variável discreta, medida em anos) e educação (variável em sete níveis de estudo, desde "1", sem estudos, até "7", com superior completo ou pós-graduação).

Para que fosse possível testar a teoria das pistas partidárias, os surveys aqui analisados também precisavam contemplar a variável de conexão entre os dados individuais e os do sistema de partidos brasileiro. A questão utilizada foi a que interrogava os entrevistados sobre seu partido de preferência7: PMDB, PT, PPB, PSDB, PTB, PRN, PDT, PSB, PFL, PL ou nenhum. Salvo o PRN, com poucos simpatizantes durante o período, todos os demais foram incluídos na análise ${ }^{8}$.

No nível partidário, a variável fundamental deste artigo é a posição desses nove partidos na dimensão governo-oposição. Para captar essas posições, utilizei o Índice de Apoio ao Governo (IAG), proposto por Nicolau (2000). Esse índice é a razão entre o número

\footnotetext{
${ }^{6}$ A redação das questões era a seguinte: "Na sua opinião, daqui para frente a inflação vai aumentar, diminuir ou ficar como está?" e "E o desemprego, vai aumentar, diminuir ou ficar como está?".

7 Vale registrar também que o vínculo aqui observado não é de identidade partidária (Campbell et al., 1960) ou de ativismo (Norris, 2002), mas simplesmente de preferência ou simpatia.

8 Em média, os partidos tiveram os seguintes números de simpatizantes a cada survey: PSDB (442), PFL (497), PMDB (1.316), PPB (128), PTB (145), PL (39), PSB (62), PDT (284) e PT (1.972).
} 
de deputados de cada partido que vota segundo a indicação do líder do governo e o número total de cadeiras do partido. Seguindo Nicolau (2000), não foram consideradas no cálculo as votações simbólicas; as que não obtiveram quórum necessário para deliberação; as que não tiveram conflito (i.e., em que a maioria obteve $90 \%$ dos votos ou mais); e aquelas sobre temas regimentais (e.g., requerimentos de urgência). Em uma votação "v", na qual 20 dos 40 deputados de um partido votaram seguindo a orientação do líder do governo, o índice é de 0,5. Ao longo de um período "t", o IAG é a média do índice de apoio em todas as votações ("V") ${ }^{9}$. Nos anos em que os surveys utilizados foram realizados em dezembro, computou-se o IAG de votações de todo o ano. Para 2000, entretanto, foi utilizado o IAG acumulado do primeiro semestre, uma vez que, como dito (ver nota 5), os demais surveys daquele ano não tinham a questão sobre preferência partidária ${ }^{10}$. Não assumo, porém, que os indivíduos saibam ou acompanhem as votações nominais de seus partidos preferidos na Câmara dos Deputados. Apenas utilizo esses dados como variável proxy para posicionar cada legenda no eixo governo-oposição medido pelo Índice de Apoio ao Governo.

A dinâmica do IAG durante o governo FHC permite separar os partidos em três grupos: um grupo governista (PSDB, PFL, PMDB, PPB e PTB, com apoio entre $60 \%$ e $80 \%$ ), o PL (que gradualmente foi retirando seu apoio ao governo) e um grupo oposicionista (PSB, PDT e PT, com apoio inferior a 20\%), no qual a única exceção foi o PT em 2002, que apoiou o governo em $39 \%$ das votações, grande parte delas depois da vitória de Lula nas eleições presidenciais daquele ano e devido à necessidade de melhorar as condições fiscais antes do início do governo petista em 2003.

A Figura 1 apresenta oito gráficos de correlação entre o IAG e a média de aprovação do governo FHC entre os simpatizantes dos nove partidos, ano a ano, entre 1995 e 2002, além da média de todo o período 1995-2002. Os coeficientes de correlação são em geral altos $(0,68 \leq r \leq 0,93)$, o que sugere que as opiniões dos simpatizantes dos partidos políticos brasileiros correspondiam em grande medida à posição legislativa de seus partidos políticos preferidos em votações na Câmara dos Deputados. A seção seguinte oferecerá um teste mais robusto dessa associação ao analisar modelos multivariados que incorporam não apenas variáveis de controle, mas também variáveis objetivas - sobre o desempenho da inflação e do desemprego - e subjetivas - sobre a avaliação retrospectiva e prospectiva dos brasileiros a respeito da economia.

\footnotetext{
9 Para uma visão alternativa a essa operacionalização, ver Pereira e Mueller (2003).

10 Os valores do IAG de cada partido durante o primeiro mandato de Cardoso (1995-1998) foram calculados por Nicolau (2000). Os valores do IAG para cada partido durante o segundo mandato (1999-2002) foram calculados por mim a partir da análise de 484 votações nominais realizadas nesse período, disponíveis no site da Câmara dos Deputados (<https://www2.camara.leg.br/atividadelegislativa/plenario/resultadoVotacao>). Seguindo os critérios de Nicolau, não considerei para o cálculo do IAG as votações que não tiveram quórum suficiente para deliberação, as que não tiveram conflito (i.e., a maioria alcançou $90 \%$ ou mais dos votos) ou as que constituíam simplesmente trâmites regimentais (e.g., requerimentos de urgência). As votações de alterações constitucionais exigem um quórum de 308 votos; as leis complementares, 257 votos; e as leis ordinárias e medidas provisórias, a maioria dos presentes (cujo mínimo, na prática, varia entre 129 e 257 votos).
} 
Figura 1

Gráficos de dispersão entre o Índice de Apoio ao Governo (IAG) do sistema de partidos brasileiro e a avaliação do governo FHC por seus simpatizantes (1995-2002)

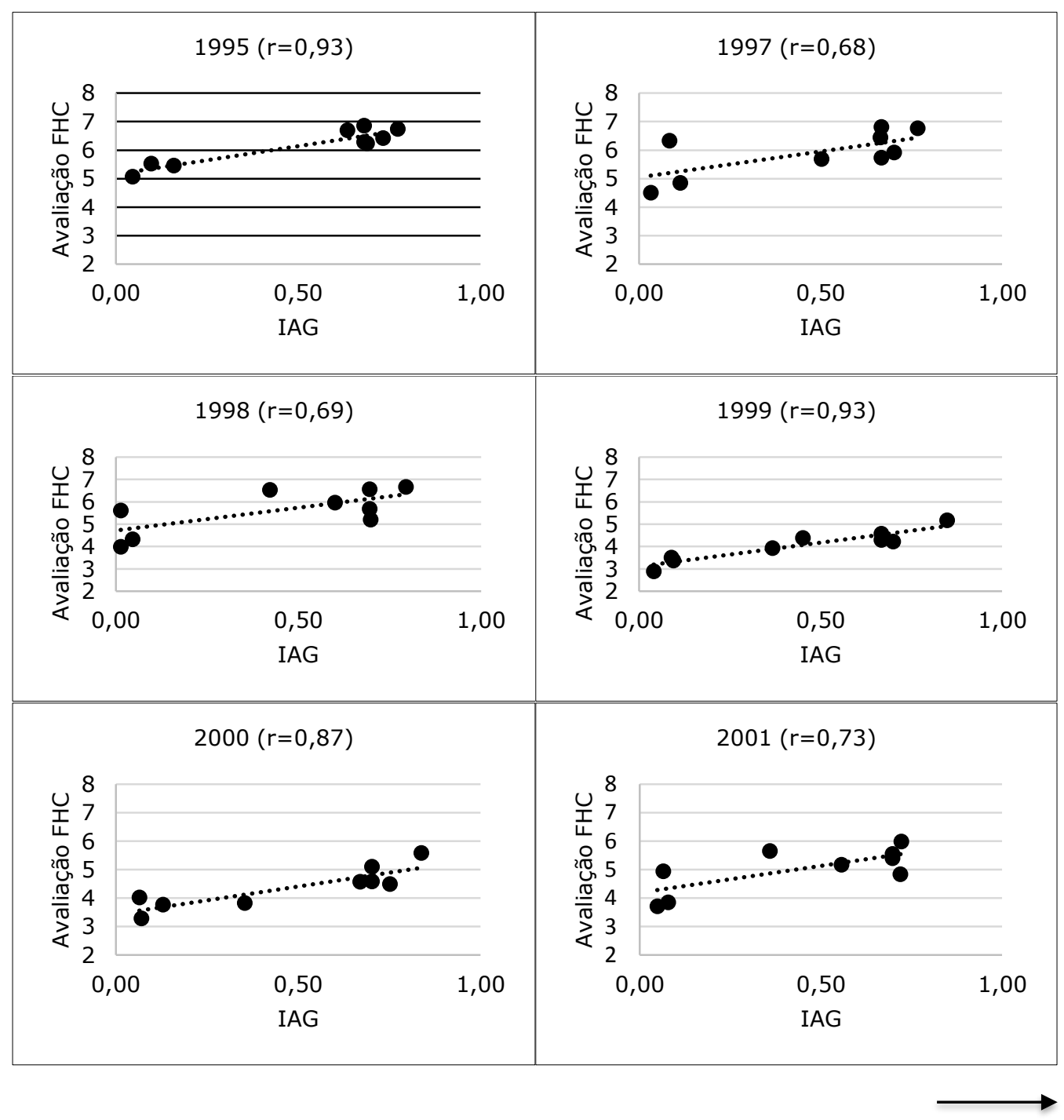




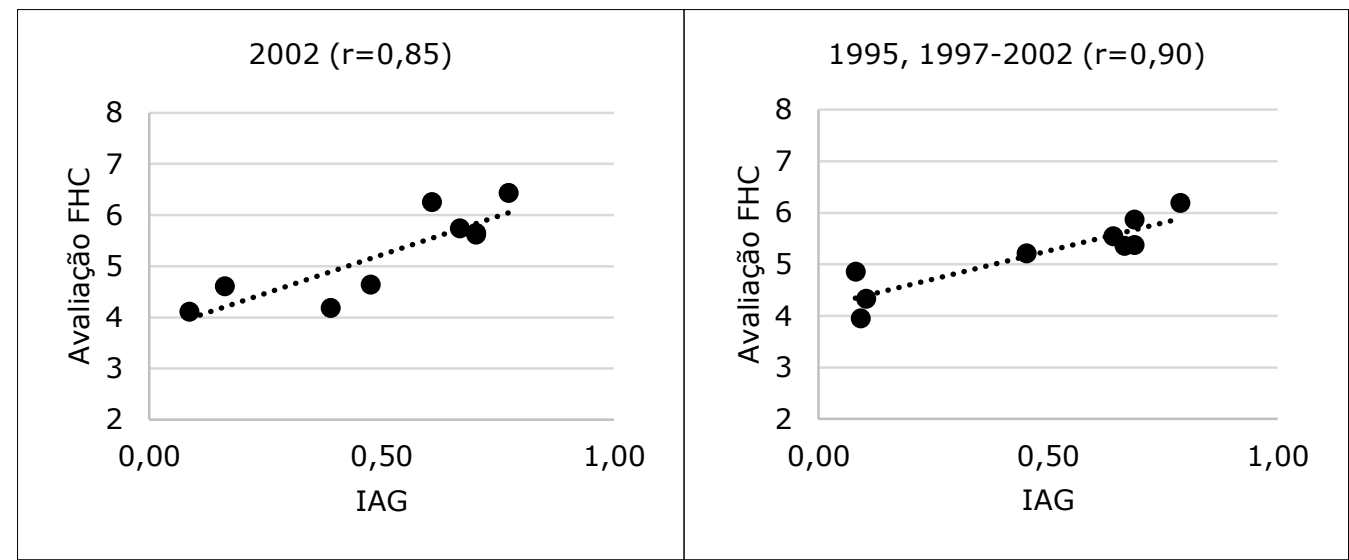

Fonte: Elaboração do autor com base em dados dos surveys do Datafolha para a avaliação de FHC (1995, 1997-2002), em Nicolau (2000) para o IAG de 1995 a 1998, e na análise de 484 votações nominais na Câmara dos Deputados para o IAG de 1999 a 2002.

Para mensurar o protagonismo de cada partido político na imprensa, foi construído um Índice de Relevância Midiática (IRM), que se baseou no conteúdo informativo publicado pelo jornal Folha de S. Paulo no período 1995-2002. Esse índice registra, em cada ano (ou semestre, no caso dos dados de 2000), o número de citações para cada um dos nove partidos em notícias sobre o governo FHC. Um IRM de 0,2 para o partido "p" no período "t" informa que, ao longo desse período, 20\% das menções aos nove partidos em notícias sobre o governo FHC corresponderam ao partido " $p$ "11. Os dados revelam que, no período FHC, o IRM separou os nove partidos analisados em dois grupos distintos, um com maior protagonismo midiático (PSDB, PFL, PMDB e PT, que juntos somavam ao menos $80 \%$ das citações a cada ano) e outro com importância secundária (PPB, PTB, PL, PSB e PDT, cuja soma das citações não superou $20 \%$ em nenhum ano). No período analisado, o PT foi o partido que mais aumentou seu IAG (de 15\% em 1995 para 26\% em 2002), enquanto o PPB foi o que mais perdeu espaço (de $11 \%$ em 1995 para $4 \%$ em 2002).

O conteúdo publicado pela Folha também é considerado aqui como uma variável proxy do conteúdo divulgado pelo conjunto da mídia. Por um lado, cabe reconhecer que não se pode advogar que esse conteúdo seja a priori representativo do contexto midiático nacional, cada vez mais fragmentado em termos regionais e de suportes midiáticos (Gramacho e Jácomo, 2015). Por outro lado, com base em estudos anteriores, assume-se que o conteúdo de jornais de referência nacional como a Folha - o mais lido pelos deputados federais (FSB Comunicação, 2019) -, por exemplo, tem forte correlação com o conteúdo do sistema midiático como um todo, dada a capacidade de alguns veículos de influenciarem a agenda intermidiática (Mundim, 2010; Denham, 2014).

\footnotetext{
11 As pesquisas na base de dados do jornal incluíram as siglas dos nove partidos estudados e os critérios "governo" e "FHC", sigla utilizada pela Folha e outros jornais para referir-se ao presidente Fernando Henrique Cardoso.
} 
Finalmente, as variáveis de nível conjuntural contempladas neste estudo são as condições de inflação, medida pelo Índice Nacional de Preços ao Consumidor (INPC), acumulada nos 12 meses anteriores à realização do survey, e de desemprego, com base na média mensal da Taxa de Desemprego Aberto em 30 dias dos 12 meses anteriores à realização do survey. Os indicadores de inflação e desemprego, conhecidos como "the big two" (Lewis-Beck e Paldam, 2000), são com frequência associados à aprovação dos governos. A inflação caiu na maior parte da administração de FHC, com uma alta importante no último ano de sua gestão, em 2002. Já o desemprego teve tendência de crescimento durante todo o período, fruto da retração da atividade econômica causada pela política monetária restritiva. A próxima seção apresenta a estratégia multinível de análise dos dados e discute os resultados de modelos de regressão.

\section{Análise multinível: modelos e discussão de resultados}

A análise multinível (Kreft e Leeuw, 1998; Snijders e Bosker, 1999; Luke, 2004) não considera que as observações individuais sejam independentes entre si, mas que podem ter algum nível de associação, seja porque os indivíduos compartilham o mesmo distrito eleitoral (Jones, Johnston e Pattie, 1992) ou contexto político (Anderson e Tverdova, 2003), seja porque simpatizam com os mesmos partidos (Steenbergen e Jones, 2002). A ideia subjacente a esses modelos é que as características dos grupos (i.e., que simpatizam com um mesmo partido ou que responderam a um survey num mesmo contexto macroeconômico) têm efeitos sobre a opinião ou o comportamento dos indivíduos. Do ponto de vista estatístico, uma vantagem da análise multinível é que ela permite corrigir o erro-padrão dos coeficientes estimados, ao considerar os erros compartilhados por observações retiradas de um mesmo grupo ou contexto. Num modelo de mínimos quadrados ordinários, a chance de encontrar um coeficiente estatisticamente significativo é maior, devido à redução artificial do erro-padrão estimado, aumentando, assim, as chances de cometimento de erros de Tipo I.

Neste artigo, as 34.193 entrevistas obtidas em surveys constituem dados de nível 1 (individuais). Os simpatizantes de um mesmo partido foram agrupados em variáveis de nível 2 (partidárias), com 63 observações (9 partidos $x 7$ anos). Por sua vez, a cada survey foram imputadas variáveis de nível 3 (contextual), que descrevem as condições macroeconômicas nas quais foi realizada a pesquisa. Esse último nível, portanto, tem apenas sete observações. Como uma análise que explorasse todas as possíveis interações entre três níveis (com seis variáveis individuais, duas variáveis partidárias e outras duas variáveis conjunturais) resultaria em modelos complexos e pouco compreensíveis, a opção nessa etapa foi buscar uma solução parcimoniosa para explicar a popularidade do governo FHC, guiada pelo teste das hipóteses anteriormente formuladas ${ }^{12}$.

\footnotetext{
12 Vale registrar que um teste prévio analisou a direção causal das pistas partidárias no período FHC, seguindo o método utilizado por Carrubba (2001) e Edwards et al. (2005). Uma análise de mínimos quadrados em
} 
A Tabela 2 reúne um modelo nulo e sete outros modelos com diferentes especificações que testam as hipóteses deste artigo. O modelo nulo [0] mostra a proporção da variância na popularidade do governo FHC em cada nível de análise. Como esperado, a maior parte da variância - 87,9\% - se deu no nível 1 (individual). Ainda assim, uma fração teoricamente expressiva da variância foi registrada no nível 2 (partidário), de 7,0\%, e no nível 3 (conjuntural), de 5,1\%. Segundo Snijders e Bosker (1999, p. 46), uma análise multinível é justificável quando ao menos $5 \%$ da variância da variável dependente está associada ao nível $2^{13}$. Além disso, uma segunda razão para usar um modelo multinível é que ele não se baseia no pressuposto de modelos de mínimos quadrados ordinários (MQO), segundo os quais os erros em nível individual são independentes entre si. Modelos multiníveis consideram que parte dos erros individuais é compartilhada por indivíduos de um mesmo grupo ou contexto social. A Tabela 2, a seguir, apresenta os testes de hipóteses.

duas etapas (2SLS, two-stage least squares) indicou que o IAG dos nove partidos políticos observados não respondeu às variações na média de aprovação da gestão entre os simpatizantes de cada partido durante o período 1995-2002. Ao contrário, foram as opiniões dos simpatizantes dos partidos que estiveram associadas ao nível agregado de apoio de cada legenda ao governo.

13 Em estudo também com três níveis, Steenbergen e Jones (2002, p. 231) indicaram que 5,8\% da variância da avaliação dos europeus a respeito da União Europeia correspondia ao nível partidário (nível 2) e 15,3\%, ao nível nacional (nível 3). 
Tabela 2

Modelos multiníveis de avaliação do governo FHC

\begin{tabular}{|c|c|c|c|c|c|c|c|c|}
\hline & [0] & [1] & [2] & [3] & [4] & [5] & {$[6]$} & [7] \\
\hline \multicolumn{9}{|l|}{ Efeitos fixos } \\
\hline \multicolumn{9}{|l|}{ Nível 1 (individual) } \\
\hline $\begin{array}{l}\text { Avaliação do Plano } \\
\text { Real }\end{array}$ & - & $\begin{array}{c}1,455^{* * *} \\
(, 073)\end{array}$ & $\begin{array}{c}1,454 * * * \\
(, 019)\end{array}$ & $\begin{array}{c}1,455 * * * \\
(, 019)\end{array}$ & $\begin{array}{c}1,446 * * * \\
(, 019)\end{array}$ & $\begin{array}{c}1,445^{* * *} \\
(, 019)\end{array}$ & $\begin{array}{c}1,445^{* * *} \\
(, 019)\end{array}$ & $\begin{array}{c}1,445 * * * \\
(, 019)\end{array}$ \\
\hline $\begin{array}{l}\text { Expectativa sobre a } \\
\text { inflação }\end{array}$ & - & $\begin{array}{l}235 \\
(, 134)\end{array}$ & $\begin{array}{c}, 234 * * * \\
(, 022)\end{array}$ & $\begin{array}{c}, 234 * * * \\
(, 022)\end{array}$ & $\begin{array}{c}, 231 * * * \\
(, 022)\end{array}$ & $\begin{array}{c}, 230 * * * \\
(, 022)\end{array}$ & $\begin{array}{c}, 230 * * * \\
(, 022)\end{array}$ & $\begin{array}{c}, 230 * * * \\
(, 022)\end{array}$ \\
\hline $\begin{array}{l}\text { Expectativa sobre o } \\
\text { desemprego }\end{array}$ & - & $\begin{array}{l}, 262^{* *} \\
(, 084)\end{array}$ & $\begin{array}{c}, 260 * * * \\
(, 019)\end{array}$ & $\begin{array}{c}, 260 * * * \\
(, 019)\end{array}$ & $\begin{array}{l}, 254 * * * \\
(, 019)\end{array}$ & $\begin{array}{c}254 * * * \\
(, 019)\end{array}$ & $\begin{array}{c}253 * * * \\
(, 019)\end{array}$ & $\begin{array}{c}, 254 * * * \\
(, 019)\end{array}$ \\
\hline Gênero (mulher) & - & $\begin{array}{l}-, 001 \\
(, 022)\end{array}$ & $\begin{array}{l}-, 003 \\
(, 028) \\
\end{array}$ & $\begin{array}{l}-, 004 \\
(, 028) \\
\end{array}$ & $\begin{array}{l}-, 002 \\
(, 028) \\
\end{array}$ & $\begin{array}{l}-, 001 \\
(, 028)\end{array}$ & $\begin{array}{l}-, 001 \\
(, 028)\end{array}$ & $\begin{array}{l}-, 001 \\
(, 028) \\
\end{array}$ \\
\hline Idade & - & $\begin{array}{l}1002 \\
(, 002)\end{array}$ & $\begin{array}{l}002 \\
(, 001)\end{array}$ & $\begin{array}{l}(001 \\
(, 001)\end{array}$ & $\begin{array}{c}-, 012 * * * \\
(, 002)\end{array}$ & $\begin{array}{c}-, 012 * * * \\
(, 002)\end{array}$ & $\begin{array}{c}-, 012 * * * \\
(, 002)\end{array}$ & $\begin{array}{c}-, 012 * * * \\
(, 002)\end{array}$ \\
\hline Escolaridade & - & $\begin{array}{l}-, 028 \\
(, 023)\end{array}$ & $\begin{array}{c}-, 027 * * * \\
(, 008)\end{array}$ & $\begin{array}{l}-, 016 \\
(, 014)\end{array}$ & $\begin{array}{c}-, 027 * * \\
(, 008) \\
\end{array}$ & $\begin{array}{c}-, 027 * * \\
(, 008) \\
\end{array}$ & $\begin{array}{c}-, 027 * * \\
(, 008) \\
\end{array}$ & $\begin{array}{c}-, 027 * * \\
(, 008) \\
\end{array}$ \\
\hline \multicolumn{9}{|l|}{ Nível 2 (partidário) } \\
\hline $\begin{array}{l}\text { Índice de Apoio ao } \\
\text { Governo } \\
\text { (IAG) }\end{array}$ & - & - & $\begin{array}{c}1,521 * * * \\
(, 129)\end{array}$ & $\begin{array}{c}1,522 * * * \\
(, 129)\end{array}$ & $\begin{array}{c}1,502 * * * \\
(, 134)\end{array}$ & $\begin{array}{l}, 474 \\
(, 251)\end{array}$ & $\begin{array}{l}, 473 \\
(, 251)\end{array}$ & $\begin{array}{l}, 487 \\
(, 251)\end{array}$ \\
\hline $\begin{array}{l}\text { Indice de Relevância } \\
\text { Midiática (IRM) }\end{array}$ & - & - & - & - & - & $\begin{array}{c}-4,775 * * * \\
(, 959)\end{array}$ & $\begin{array}{c}-4,773 * * * \\
(, 960)\end{array}$ & $\begin{array}{c}-4,715^{* * * *} \\
(, 957)\end{array}$ \\
\hline IAG $*$ IRM & - & - & - & - & - & $\begin{array}{c}8,520 * * * \\
(1,674)\end{array}$ & $\begin{array}{c}8,521 * * * \\
(1,675)\end{array}$ & $\begin{array}{c}8,418^{* * *} \\
(1,670)\end{array}$ \\
\hline \multicolumn{9}{|l|}{$\begin{array}{l}\text { Nível } 3 \\
\text { (conjuntural) }\end{array}$} \\
\hline Inflação & - & - & - & - & - & - & $\begin{array}{l}, 026 \\
(, 026)\end{array}$ & - \\
\hline Desemprego & - & - & - & - & - & - & - & $\begin{array}{l}-, 297 * \\
(, 091)\end{array}$ \\
\hline \multicolumn{9}{|l|}{$\begin{array}{l}\text { Interações } \\
\text { interníveis }\end{array}$} \\
\hline $\begin{array}{l}\text { Escolaridade (Nível } \\
\text { 1) } \\
\text { * IAG (Nível 2) }\end{array}$ & - & - & - & $\begin{array}{l}-, 027 \\
(, 026)\end{array}$ & - & - & - & - \\
\hline $\begin{array}{l}\text { Idade (Nível 1) } \\
\text { * IAG (Nível 2) }\end{array}$ & - & - & - & - & $\begin{array}{c}1,029 * * * \\
(, 003)\end{array}$ & $\begin{array}{c}030 * * * \\
(, 003)\end{array}$ & $\begin{array}{c}030 * * * \\
(, 003)\end{array}$ & $\begin{array}{c}, 030 * * * \\
(, 003)\end{array}$ \\
\hline \multicolumn{9}{|l|}{$\begin{array}{l}\text { Componentes da } \\
\text { variância }\end{array}$} \\
\hline Constante & $\begin{array}{c}5,183 * * * \\
(, 272)\end{array}$ & $\begin{array}{c}, 965 * * * \\
(, 193) \\
\end{array}$ & $\begin{array}{c}4,217 * * * \\
(, 182) \\
\end{array}$ & $\begin{array}{c}4,216 * * * \\
(, 182) \\
\end{array}$ & $\begin{array}{c}4,222 * * * \\
(, 182) \\
\end{array}$ & $\begin{array}{c}4,729 * * * \\
(, 212) \\
\end{array}$ & $\begin{array}{c}4,483 * * * \\
(, 321)\end{array}$ & $\begin{array}{c}6,871 * * * \\
(, 682) \\
\end{array}$ \\
\hline$\sigma^{2}$ (Nível 1) & $\begin{array}{c}7,739 \\
(2,782)\end{array}$ & $\begin{array}{c}6,414 \\
(2,533) \\
\end{array}$ & $\begin{array}{c}6,415 \\
(2,533) \\
\end{array}$ & $\begin{array}{c}6,415 \\
(2,533) \\
\end{array}$ & $\begin{array}{c}6,399 \\
(2,530) \\
\end{array}$ & $\begin{array}{c}6,398 \\
(2,529) \\
\end{array}$ & $\begin{array}{c}6,398 \\
(2,529)\end{array}$ & $\begin{array}{c}6,398 \\
(2,529)\end{array}$ \\
\hline Too (Nível 2) & $\begin{array}{c}, 615 * * * \\
(, 784)\end{array}$ & $\begin{array}{l}290 * * * \\
(, 538)\end{array}$ & $\begin{array}{c}, 064 * * * \\
(, 254)\end{array}$ & $\begin{array}{c}, 065 * * * \\
(, 255)\end{array}$ & $\begin{array}{c}, 070 * * * \\
(, 265)\end{array}$ & $\begin{array}{c}, 040 * * * \\
(, 199)\end{array}$ & $\begin{array}{c}, 040 * * * \\
(, 199)\end{array}$ & $\begin{array}{c}, 039 * * * \\
(, 199)\end{array}$ \\
\hline$\omega_{00}$ (Nível 3) & $\begin{array}{c}445 * * * \\
(, 667)\end{array}$ & $\begin{array}{c}168 * * * \\
(, 410)\end{array}$ & $\begin{array}{c}191 * * * \\
(, 437)\end{array}$ & $\begin{array}{c}190 * * * \\
(436)\end{array}$ & $\begin{array}{c}189 * * * \\
(, 434)\end{array}$ & $\begin{array}{c}207 * * * \\
(, 455)\end{array}$ & $\begin{array}{c}181 * * * \\
(, 425)\end{array}$ & $\begin{array}{c}1078 * * * \\
(, 280)\end{array}$ \\
\hline $\begin{array}{l}\text { Deviance } \\
\text { (parâmetros) }\end{array}$ & $\begin{array}{c}167218 \\
(4)\end{array}$ & $\begin{array}{c}160763 \\
(10)\end{array}$ & $\begin{array}{c}160703 \\
(11)\end{array}$ & $\begin{array}{c}160702 \\
(12)\end{array}$ & $\begin{array}{c}160619 \\
(12)\end{array}$ & $\begin{array}{c}160596 \\
(14)\end{array}$ & $\begin{array}{c}160596 \\
(15)\end{array}$ & $\begin{array}{c}160590 \\
(15)\end{array}$ \\
\hline
\end{tabular}

Fonte: Elaboração do autor com base na análise dos bancos indicados na seção "Os dados e o governo FHC".

Nota: A tabela mostra os coeficientes de efeitos fixos (com seus erros-padrão entre parênteses) e os componentes da variância (com seus desvios-padrão entre parênteses). * Significativo ao nível ,05; ** significativo ao nível ,01; $* * *$ significativo ao nível ,001. 
O modelo [1] está composto apenas por variáveis de nível 1 (individual). Seus resultados sugerem que a aprovação ao governo FHC esteve associada ao juízo dos brasileiros a respeito do Plano Real e suas expectativas em relação ao comportamento futuro da inflação e do desemprego. O coeficiente da variável de expectativa sobre inflação não é estatisticamente significativo nesse primeiro modelo; mas, com a inclusão das demais variáveis nos modelos seguintes, ele passa a ser significativo e tem comportamento estável. Por isso, considera-se que não se podem descartar as hipóteses H5 (voto econômico subjetivo retrospectivo), H6 (voto econômico subjetivo prospectivo, inflação) e H7 (voto econômico subjetivo prospectivo, desemprego), indicadas anteriormente, resultado que apoia as teorias do voto econômico e das funções de popularidade, reforçando também o pressuposto de que o desenho de pesquisa tinha na economia um forte concorrente para a hipótese central da teoria das pistas partidárias como fonte alternativa de informação e opinião para que os brasileiros avaliassem o governo FHC.

O teste crucial deste artigo, contudo, aparece nos modelos de [2] a [5]. O modelo [2] mostra que o Índice de Apoio ao Governo (IAG), que registra a posição do sistema de partidos brasileiro em votações de interesse do Executivo na Câmara dos Deputados, esteve associado à opinião de seus simpatizantes sobre a gestão de FHC. Além disso, os coeficientes de nível 1 praticamente não sofreram variações em relação ao modelo [1], o que sugere que a variância explicada pelo IAG tem outra natureza, mais bem capturada por uma análise multinível. Esse resultado não permite, portanto, descartar a hipótese da existência de pistas partidárias no Brasil sobre um easy issue, como a avaliação do governo federal (H1), e pode ser entendido como evidência empírica de que os partidos políticos mesmo em um sistema em que seu enraizamento social é reconhecidamente frágil podem influenciar as opiniões de seus simpatizantes.

Para melhor interpretar os resultados da análise, foram elaborados três gráficos (Figura 2) que ilustram os efeitos de variáveis significativas sobre a popularidade de FHC (Hox, 1995). Em todos os casos, os valores fixos das estimativas tomaram o indivíduo médio/modal da amostra: homem, 34 anos, com ensino fundamental completo, pessimista quanto ao futuro da inflação e do desemprego e neutro em relação ao Plano Real. O Gráfico 1 simula os efeitos da variação da avaliação do Plano Real para os valores mínimo e máximo do IAG, com base nos coeficientes obtidos no modelo [2]. Isto é, a Figura 2 ilustra - efeito combinado do juízo econômico retrospectivo sobre o Plano Real para os simpatizantes de um partido que registrou valor mínimo no IAG (o PSB, em 1998, com 0,02 ) e para os simpatizantes de um partido que registrou valor máximo no IAG (o PSDB, em 1999, com 0,85).

A Figura 2 mostra que, diante de avaliações negativas ("ruim" ou "péssimo") sobre - Plano Real, simpatizantes de partidos muito oposicionistas ou muito governistas reprovariam a gestão de $\mathrm{FHC}$, dando notas abaixo de 5 (respectivamente, 2,29 e 3,55) numa escala de 0 a 10. Já indivíduos satisfeitos com o Plano Real, que o avaliassem como "ótimo" ou "bom", tenderiam a aprovar o governo, com independência em relação à 
posição das legendas com que simpatizam, dando notas acima de 5 (5,19 e 6,46, respectivamente). Entretanto, para indivíduos que avaliassem o Plano Real como "regular" ou fossem indiferentes em relação ao plano econômico, a posição de seu partido preferido pode ter tido uma influência decisiva. A simulação sugere que simpatizantes de um partido muito oposicionista dariam nota 3,74 ao governo $\mathrm{FHC}$, reprovando-o, enquanto os que preferissem um partido muito governista teriam dado 5,0, no nível crítico, limítrofe entre a reprovação e a aprovação.

Figura 2

Simulações interativas do efeito das pistas partidárias sobre a avaliação do governo FHC

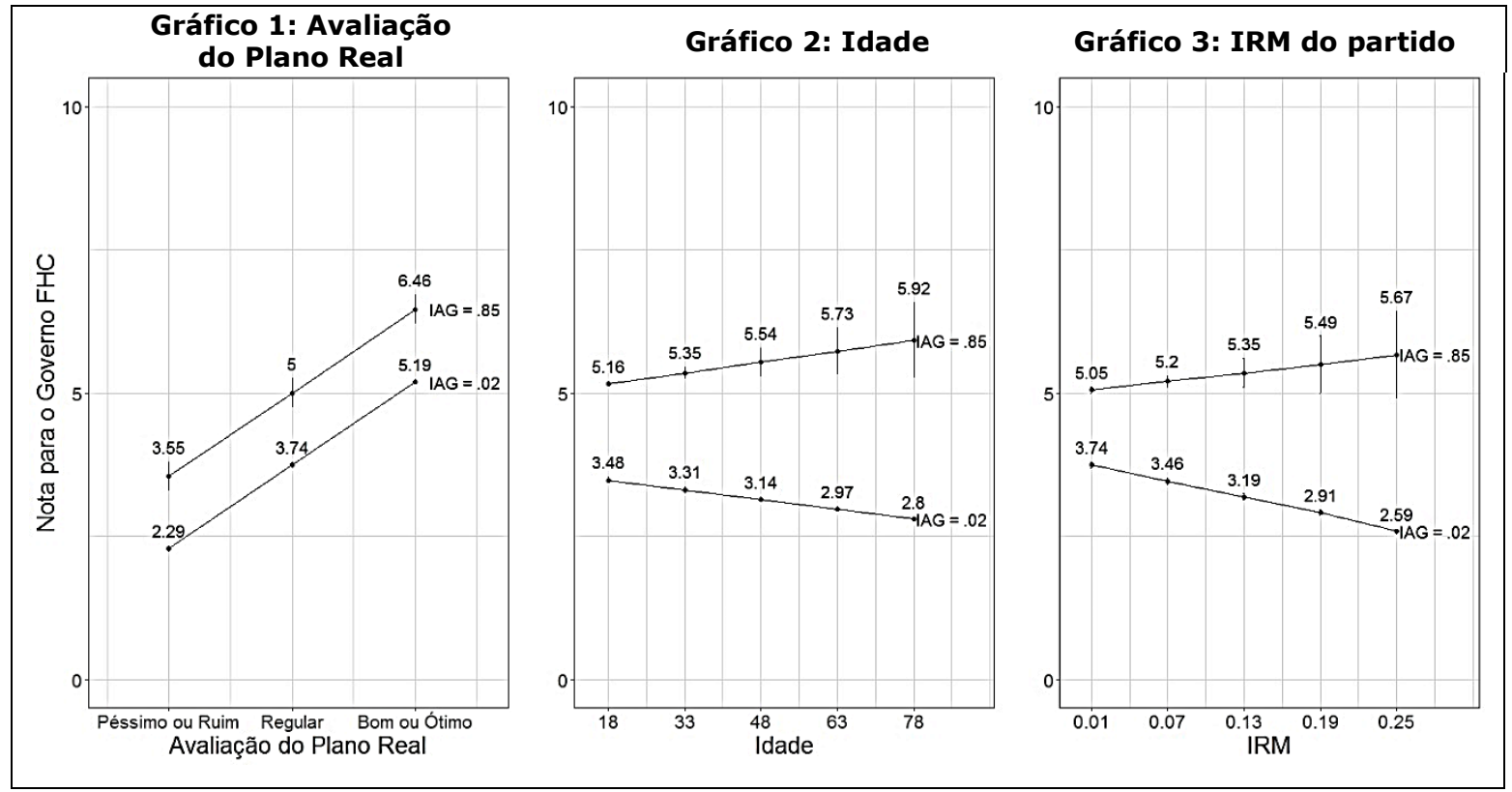

Fonte: Elaboração do autor com base na análise dos bancos indicados na seção "Os dados e o governo FHC".

Os modelos [3] e [4] testaram as hipóteses de que as pistas partidárias são moderadas pela escolaridade $(\mathrm{H} 3)$ e pela idade $(\mathrm{H} 4)$ dos indivíduos. Os resultados sugerem que, no caso da avaliação do governo FHC, o IAG não foi moderado pelo nível de escolaridade dos entrevistados, mas sim por sua idade. Ou seja, indivíduos mais idosos foram "mais sensíveis" ao IAG de seus partidos, conforme ilustrado pelo Gráfico 2. Dois indivíduos de 18 anos, com características idênticas nas demais variáveis do modelo, teriam uma diferença de opinião sobre o governo $\mathrm{FHC}$ de 1,68 ponto $(5.16$ - 3.48) se um deles simpatizasse com um partido com IAG de 0,02 e outro com uma legenda com IAG de 0,85 . Aos 78 anos, essa mesma diferença teria sido de expressivos 3,12 pontos (5.92 - 2.80). Esses testes não apoiam, portanto, a hipótese sobre o efeito do nível de 
escolaridade nas pistas partidárias (H3), mas reforçam a expectativa expressa em H4, de que indivíduos mais velhos serão mais influenciados.

Para além de características individuais que afetam as pistas partidárias, este artigo sugere, especificamente, que a associação entre as posições dos partidos e as opiniões de seus simpatizantes deve ser moderada pela relevância midiática de cada legenda (H2). O teste dessa hipótese está no modelo [5], reforçado pelos modelos [6] e [7]. De fato, a associação entre o IAG e a popularidade do governo FHC parece ter sido moderada pelo Índice de Relevância Midiática (IRM) de cada partido. Ou seja, as opiniões de simpatizantes de um partido governista e um oposicionista eram tão mais distantes quanto maior o protagonismo dessas agremiações no debate midiático, conforme ilustrado pelo Gráfico $3^{14}$. A diferença de avaliação do governo $\mathrm{FHC}$ entre simpatizantes de partidos muito oposicionistas (IAG $=0,02$ ) e simpatizantes de partidos muito governistas (IAG = $0,85)$ teria sido de apenas 1,31 ponto $(5,05-3,74)$ se o IRM de ambos fosse baixo, de 0,01 , indicando que cada uma das legendas teve apenas $1 \%$ das citações aos nove partidos na cobertura da Folha sobre o governo FHC no período anterior à realização do survey. Entretanto, se essas mesmas siglas tivessem um IRM de 0,26, a diferença de opinião entre seus respectivos simpatizantes hipotéticos teria sido mais que o dobro, de 3,08 pontos $(5,67-2,59)$.

Finalmente, os modelos [6] e [7] - além de reforçarem os achados quanto ao efeito moderador da mídia sobre as pistas partidárias - testaram as hipóteses de que a popularidade de FHC esteve associada ao desempenho objetivo dos indicadores de inflação (H8) e desemprego (H9). Os resultados não apoiam H8, pois o coeficiente não é significativo e está na direção contrária ao esperado. Depois de anos de hiperinflação, parece compreensível que os indivíduos não tenham castigado o governo por variações moderadas nos preços, que durante o período FHC estiveram abaixo dos $10 \%$ em seis dos oito anos de administração. O modelo [7], entretanto, não permite descartar a hipótese H9, uma vez que o coeficiente do estado do desemprego prévio a cada survey é estatisticamente significativo e mostra que a aprovação de FHC foi mais baixa quando o desemprego estava mais alto.

Em resumo, as análises realizadas nesta seção podem ser resumidas em quatro achados relevantes. Em primeiro lugar, os resultados oferecem evidência empírica a favor da teoria das pistas partidárias, num contexto adverso ao seu teste, como o da aprovação ao governo FHC no Brasil em tempos de estabilização econômica. Pode-se considerar, portanto, que a popularidade do governo FHC talvez não tenha sido influenciada apenas pelo seu desempenho econômico e pelas expectativas causadas nos indivíduos quanto ao comportamento futuro da inflação e do desemprego, mas também pelas posições do sistema de partidos políticos na dimensão governo-oposição durante seus dois mandatos.

\footnotetext{
14 Os valores para a simulação do efeito do IRM são 0,01 (registrado pelo PL no período 1997-2000) e 0,26 (registrado pelo PT em 2002).
} 
A influência das pistas partidárias, no entanto, parece não ter sido a mesma para todos os indivíduos nem para todos os partidos. Indivíduos mais velhos registraram maior efeito das pistas partidárias, talvez por estarem expostos por mais anos a processos de persuasão política e poderem estabelecer padrões de interação continuada com suas legendas preferidas (ainda que numa democracia recente). E partidos com maior relevância midiática tiveram maior influência sobre as opiniões de seus simpatizantes. Nesse aspecto, os dados sugerem uma vantagem do PT sobre as demais siglas analisadas neste estudo, uma vez que seus valores associados à variável IRM cresceram ao longo do tempo (de 0,15 em 1995 para 0,26 em 2002). Apesar de ser percebido como um partido com maior vínculo com seus simpatizantes que os demais, uma análise de resíduos do modelo [7] não sugere um desempenho melhor do PT em relação às demais agremiações, uma vez incluídas as variáveis IRM e IAG no modelo. Ou seja, se o PT teve maior influência que outros partidos na opinião de seus simpatizantes sobre o governo $\mathrm{FHC}$, isso se deveu provavelmente ao fato de que teve maior relevância midiática que outras legendas.

Finalmente, a análise também revelou apoio empírico às teorias do voto econômico e das funções de popularidade, uma vez que variáveis objetivas (i.e., o desemprego) e variáveis subjetivas (tanto em versões retrospectivas como prospectivas) estiveram estatisticamente associadas à aprovação do governo FHC no período analisado.

\section{Limitações}

O presente artigo apresenta algumas limitações decorrentes de seu desenho de pesquisa. A primeira delas é inferencial. A opção por um desenho observacional - e não experimental, como o de Samuels e Zucco Junior (2014) - traz limitações de reivindicação de causalidade (McDermott, 2002; Gerber et al., 2004). Apesar da existência de outras técnicas robustas - como os experimentos naturais, as regressões descontínuas e as análises de mediação -, os experimentos controlados continuam sendo o "padrão ouro" da identificação de relações causais (Keele, 2015). Ainda assim, este artigo busca contribuir para a coleção de evidências empíricas sobre a teoria das pistas partidárias e para a ampliação das hipóteses que compõem seu modelo explicativo. Como lembra Stokes (2014, p. 53), a construção teórica não envolve apenas testes de causa e efeito, mas também testes indutivos e deduções.

Em segundo lugar, vale ressaltar que este artigo não se ocupa de uma possível relação entre as posições dos partidos políticos e as opiniões de indivíduos não simpatizantes de nenhuma legenda, sejam eles antipartidários difusos ou específicos. Estes podem ter suas opiniões influenciadas pelo contexto informacional construído pelas elites políticas ou simplesmente distribuir-se de modo aleatório entre as alternativas existentes. Outros trabalhos poderão se dedicar a essa questão.

Em terceiro lugar, a análise aqui apresentada assume que as posições legislativas dos partidos concordaram com suas manifestações públicas, incluindo suas posições em 
entrevistas e pronunciamentos, e que essas posições foram assimiladas por seus simpatizantes, produzindo influência em suas opiniões sobre o governo FHC. Não assume o contrário, isto é, que as posições legislativas dos partidos foram influenciadas pelas opiniões de seus simpatizantes. O teste desse pressuposto sobre a direção causal dessa relação, contudo, constitui um tópico importante para investigações futuras sobre a teoria das pistas partidárias e sua adequação à relação entre os partidos brasileiros e seus simpatizantes.

Finalmente, uma quarta limitação decorre do fato de que os dados analisados correspondem apenas ao período $\mathrm{FHC}$, que não necessariamente representa o estado posterior do vínculo entre os partidos e seus simpatizantes no país. Ou seja, é possível que processos recentes de aumento da desconfiança em relação aos partidos em meio às crises sanitária e econômica ofereçam novas condições para testes cruciais da hipótese central da teoria das pistas partidárias.

\section{Considerações finais}

O argumento desenvolvido neste artigo é que a investigação empírica sobre a teoria das pistas partidárias durante o governo FHC constitui um teste crucial para a hipótese de que os partidos políticos podem influenciar as opiniões de seus simpatizantes. Tradicionalmente, a literatura tem olhado de forma cética para os estudos de caso (Bartolini, 1988), mal os interpretando como o estudo de uma única observação, como argumenta Rueschemeyer (2003). Todavia, o potencial dos estudos de caso ultrapassa a geração de hipóteses e a descrição de casos atípicos (Lijphart, 1971), podendo proporcionar oportunidades cruciais para testar uma teoria (Eckstein, 1975; Peters, 1998). Se não é possível obter toda a evidência empírica existente para comprovar uma teoria de modo definitivo, testá-la num contexto em que a sua aplicabilidade é muito improvável pode aumentar significativamente a confiança sobre a correção de suas hipóteses.

Os resultados descritos aqui sugerem que o sistema de partidos políticos brasileiro tem um papel importante na formação das opiniões dos indivíduos e na organização de sua visão sobre a política (Strøm e Svåsand, 1997). Mais especificamente, os dados mostram que as opiniões dos indivíduos sobre o governo FHC estiveram associadas ao posicionamento do sistema de partidos no eixo governo-oposição, mesmo em um período marcado por forte aumento do desemprego e reduzido crescimento econômico, resultado dos esforços por manter a inflação sob controle. Isto é, inclusive quando a economia era um forte determinante da avaliação governamental, tal como prevista pela teoria do voto econômico, o sistema de partidos parece ter sido uma referência influente na formação da opinião pública no país sobre a popularidade de FHC.

Portanto, se os partidos políticos podem ter influência sobre um easy issue tal qual a avaliação governamental num contexto institucional adverso como o brasileiro (i.e., presidencialismo, federalismo, multipartidarismo e personalismo, entre outras 
características) e em um período econômico como o enfrentado por FHC, também terão em outros países nos quais seus vínculos sociais e eleitorais estejam mais arraigados e em períodos em que as condições macroeconômicas sejam menos salientes.

Este artigo também revela que a associação entre as posições dos partidos e as opiniões de seus simpatizantes foi mais forte entre indivíduos idosos e, mais importante para os objetivos deste estudo, entre partidos com maior relevância no conteúdo midiático. As mudanças recentes no sistema partidário brasileiro - com a redução do poder institucional e eleitoral do PSDB e do PT e o surgimento de novas ou remodeladas legendas como o PSL e o PSD - e as transformações midiáticas que têm tornado mais marcante o uso de redes sociais digitais na comunicação política e eleitoral, entretanto, sugerem novas questões para a agenda de pesquisas sobre a teoria das pistas partidárias. Essas recentes ou reconfiguradas legendas têm maior influência sobre as opiniões e os comportamentos de seus simpatizantes que as mais longevas, como PT, PSDB e MDB? Para além da relevância midiática de cada partido, que outras características organizacionais ou programáticas podem tornar algumas legendas mais influentes entre seus simpatizantes? A comunicação direta entre partidos e indivíduos pelas redes sociais, por exemplo, produz pistas partidárias mais fortes que a comunicação intermediada pela mídia tradicional?

A resposta a essas questões pode oferecer testes adicionais quanto à influência do sistema de partidos políticos em geral, e de algumas siglas em particular, sobre as opiniões e os comportamentos de seus simpatizantes. Mesmo num país como o Brasil.

\section{Referências bibliográficas}

AlCÁNTARA, M. ¿Instituciones o máquinas ideológicas? Origen, programa y organización de los partidos políticos latinoamericanos. Barcelona: Institut de Ciències Polítiques i Socials (ICPS), 2004.

ALDRICH, J. Why parties? The origin and transformation of political parties in America. Chicago e Londres: The University of Chicago Press, 1995.

Amorim Neto, O.; Cox, G. W.; McCubbins, M. D. "Agenda power in Brazil's Câmara dos Deputados 1989-98". World Politics, vol. 55, no 4, p. 550-578, 2003.

Anderson, C.; TVerdova, Y. "Corruption, political allegiances, and attitudes toward government in contemporary democracies". American Journal of Political Science, vol. 47, no 1, p. 91-109, 2003.

BARTOLini, S. Metodología de la investigación política. In: PASQuino, G., et al. Manual de ciencia política. Madri: Alianza Editorial, 1988.

BisgaARD, M.; SLOthuUs, R. "Partisan elites as culprits? How party cues shape partisan perceptual gaps". American Journal of Political Science, vol. 62, no 2, p. 456-469, 2018.

BORGES, A. "Nacionalização partidária e estratégias eleitorais no presidencialismo de coalizão". Dados, vol. 58, no 3, p. 651-688, 2015.

BoRgeS, A.; VidigAL, R. "Do lulismo ao antipetismo? Polarização, partidarismo e voto nas eleições presidenciais brasileiras". Opinião Pública, Campinas, vol. 24, no 1, p. 53-89, abr. 2018. 
BoudreaU, C.; MACKENZIE, S. "Informing the electorate? How party cues and policy information affect public opinion about initiatives". American Journal of Political Science, vol. 58, no 1, p. 48-62, 2014.

BRAGA, M. S. S. "Eleições e democracia no Brasil: a caminho de partidos e sistema partidário institucionalizados". Revista Brasileira de Ciência Política, Brasília, no 4, p. 43-73, jul.-dez. 2010.

CAmpBelL, A., et al. The American voter. Chicago: The University of Chicago Press, 1960.

CARLIN, R. E., et al. "Public support for Latin American presidents: the cyclical model in comparative perspective". Research \& Politics, vol. 5, no 3, p. 1-8, 2018.

CARreirão, Y. "Avaliação do governo e 'voto econômico'". Lua Nova, vol. 48, p. 213-232, 1999.

"Relevant factors for the voting decision in the 2002 presidential election: an analysis of the Eseb (Brazilian Electoral Study) data". Brazilian Political Science Review, vol. 1, no 1, p. 70-101, $2007 a$.

"Identificação ideológica, partidos e voto na eleição presidencial de 2006". Opinião Pública, Campinas, vol. 13, no 2, p. 307-339, 2007b.

CARreirão, Y.; Kinzo, M. D. G. "Partidos políticos, preferência partidária e decisão eleitoral no Brasil (1989-2002)". Dados, Rio de Janeiro, vol. 47, no 1, p. 131-167, 2004.

CARrubBa, C. "The electoral connection in European Union politics". Journal of Politics, vol. 63, n 1 , p. $141-158,2001$

ChHibBer, P.; Kollman, K. The formation of national party systems: federalism and party competition in Canada, Great Britain, India, and the United States. Princeton: Princeton University Press, 2004.

DAALDER, H. Parties: denied, dismissed, or redundant? A critique. In: GUNTHER, R.; MonTERo, J. R.; LINZ, J. J. (eds.). Political parties: old concepts and new challenges. Oxford: Oxford University Press, 2002.

Dalton, R. The decline of party identifications. In: Dalton, R. J.; Wattenberg, M. P. (eds.). Parties without partisans - Political change in advanced industrial democracies. New York: Oxford University Press, 2000.

"Partisan mobilization, cognitive mobilization and the changing American electorate". UC Irvine, Center for the Study of Democracy, 2004. Disponível em:

<https://escholarship.org/uc/item/7gz6t2bb>. Acesso em: 15 jun. 2021.

DALTON, R.; WATTENBERG, M. Unthinkable democracy: political change in advanced industrial democracies. In: Dalton, R. J.; WATtenberg, M. P. (eds.). Parties without partisans - Political change in advanced industrial democracies. New York: Oxford University Press, 2000.

DANCEY, L.; SheAgley, G. "Heuristics behaving badly: party cues and voter knowledge". American Journal of Political Science, vol. 57, no 2, p. 312-325, 2013.

DAtafolha. Avaliação de Fernando Henrique Cardoso (1 ano), dezembro de 1995, Brasil. In: Banco de Dados do Cesop, pesquisa no 475. Disponível em:

<https://www.cesop.unicamp.br/por/banco_de_dados/v/1531>. Acesso em: 15 jun. 2021.

Avaliação FHC (2 anos e 11 meses), dezembro de 1997, Brasil. In: Banco de Dados do Cesop, pesquisa no 857. Disponível em:

<https://www.cesop.unicamp.br/por/banco_de_dados/v/964>. Acesso em: 15 jun. 2021. 
DATAFOLHA. Avaliação FHC, dezembro de 1998, Brasil. In: Banco de Dados do Cesop, pesquisas no 934 a no 943. Disponível em: <https://www.cesop.unicamp.br/por/banco_de_dados>. Acesso em: 15 jun. 2021.

Avaliação Presidente Fernando Henrique Cardoso, dezembro de 1999, Brasil. In: Banco de Dados do Cesop, pesquisa no 980. Disponível em:

<https://www.cesop.unicamp.br/por/banco_de_dados/v/75>. Acesso em: 15 jun. 2021.

Avaliação FHC, junho de 2000, Brasil. Disponível em:

<https://doi.org/10.5281/zenodo.5176332>. Acesso em: 15 jun. 2021.

Avaliação Presidente Fernando Henrique Cardoso, dezembro de 2001, Brasil. In: Banco de Dados do Cesop, pesquisa no 1599. Disponível em:

<https://www.cesop.unicamp.br/por/banco_de_dados/v/837>. Acesso em: 15 jun. 2021.

. Avaliação Presidente Fernando Henrique Cardoso, dezembro de 2002, Brasil. In: Banco de Dados do Cesop, pesquisa no 1839. Disponível em:

<https://www.cesop.unicamp.br/por/banco_de_dados/v/2418>. Acesso em: 15 jun. 2021.

Delli Carpini, M. X.; Keeter, S. What Americans know about politics and why it matters. New Haven, CT \& London: Yale University Press, 1996.

DENHAM, B. E. "Intermedia attribute agenda setting in the New York Times: the case of animal abuse in U.S. horse racing". Journalism \& Mass Communication Quarterly, vol. 91, p. 17-37, 2014.

DORUSSEN, H.; PALmer, H. D. The context of economic voting. In: Dorussen, H.; TAYLOR, M. (eds.). Economic voting. New York: Routledge, 2002a.

Group economic voting: a comparison of the Netherlands and Germany. In: DoRUSSEN, H.; TAYLOR, M. (eds.). Economic voting. Nova York: Routledge, 2002b.

Downs, A. An economic theory of democracy. New York: Harper \& Row Publishers, 1957.

DRUCKMAN, J. "Using credible advice to overcome framing effects". Journal of Law, Economics \& Organization, vol. 17, no 1, p. 62-82, 2001.

Druckman, J. N.; Peterson, E.; SlothuUs, R. "How elite partisan polarization affects public opinion formation". American Political Science Review, vol. 107, no 1, p. 57-79, 2013.

ECKStein, H. Case study and theory in political science. In: Greenstein, F. I.; Polsby, N. W. (eds.). Handbook of political science 7. Reading, MA: Addison-Wesley, 1975.

EDWARDS, E., et al. "Who's cueing whom? Assessing the relationship between electorate opinion and party positions on the European Union". In: Euroskepticism Conference, Amsterdam, 1-2 jul. 2005.

ELO, K.; RAPELI, L. "Determinants of political knowledge: the effects of the media on knowledge and information". Journal of Elections, Public Opinion and Parties, vol. 20, no 1, p. 133-146, 2010.

FSB Comunicação. "Hábitos de informação e monitoramento político". Mídia \& Política 2019. Ano 12 (online), 2019. Disponível em: <https://www.fsb.com.br/noticias/baixe-aqui-o-novo-midia-epolitica-2019-com-exclusividade/>. Acesso em: 15 jun. 2021.

Gerber, A., et al. The illusion of learning from observational research. In: ShAPIRO, I.; SMITH, R.; MASOUD, T. (eds.). Problems and methods in the study of politics. Cambridge: Cambridge University Press, 2004.

GramaCHO, W. "Ciclos de información y funciones de popularidad: el período Cardoso en Brasil (1995-2002)". Desarrollo Económico, vol. 45, no 177, p. 99-121, 2005. 
Gramacho, W.; Jácomo, A. "Padrões de uso dos meios de comunicação no Brasil e seu impacto sobre níveis de informação política". Debates, vol. 9, no 3, p. 11-36, 2015.

GUNTHER, R.; DiAmond, L. "Species of political parties: a new typology". Party Politics, vol. 9, n० 2, p. 167-199, 2003.

Hox, J. J. Applied multilevel analysis. Amsterdam: TT-Publikaties, 1995.

IYengar, S.; Kinder, D. News that matters. Chicago: The University of Chicago Press, 1987.

JONES, K.; JOHnston, J.; PATTIE, C. J. "People, places and regions: exploring the use of multi-level modelling in the analysis of electoral data". British Journal of Political Science, vol. 22, no 3, p. 343380, 1992.

JONES, M. P.; MAINWARING, S. "The nationalization of parties and party systems: an empirical measure and an application to the Americas". Party Politics, vol. 9, n 2, p. 139-166, 2003.

JOSLYN, M.; HAIDER-MARKEL, D. "Framing effects on personal opinion and perception of public opinion: the cases of physician-assisted suicide and social security". Social Science Quarterly, vol. 83, n' 3, p. 690-706, 2002.

KAID, L. L.; Holtz-BACHA, C. An introduction to parties and candidates on television. In: KAID, L. L.; HOLTZ-BACHA, C. (eds.). Political advertising in Western democracies: parties and candidates on television. Thousand Oaks: Sage Publications, 1995.

KEELE, L. "The statistics of causal inference: a view from political methodology". Political Analysis, vol. 23, no 3, p. 313-335, 2015.

KREFT, I.; LeEUW, J. Introducing multilevel modeling. London: Sage Publications, 1998.

LAWSON, K.; MERKL, P. Alternative organizations: environmental, supplementary, communitarian, and authoritarian. In: LAWSON, K.; MERKL, P. (eds.). When parties fail: emerging alternative organizations. Princeton: Princeton University Press, 1988.

LEWIS-BECK, M. S. Economics and elections: the major Western democracies. Ann Arbor: The University of Michigan Press, 1990.

LeWIS-BeCK, M. S.; PALDAM, M. "Economic voting: an introduction". Electoral Studies, vol. 19, no 2-3, p. $113-121,2000$.

LEWIS-BECK, M. S., et al. "The nature of economic perceptions in mass publics". Electoral Studies, vol. 3, no 3, p. 524-528, 2013.

LeWIS-BeCK, M. S.; STEGMAieR, M. "The VP-function revisited: a survey of the literature on vote and popularity functions after over 40 years". Public Choice, vol. 157, no 3, p. 367-385, 2013.

LIJPHART, A. "Comparative politics and the comparative method". American Political Science Review, vol. 65, p. $682-693,1971$.

LINZ, J. Presidential of parliamentary democracy: does it make a difference? In: LINZ, J. J.;

VAlenZUelA, A. (eds.). The failure of presidential democracy. Baltimore: The Johns Hopkins University Press, 1994.

LUKE, D. Multilevel modeling. Thousand Oaks: Sage Publications, 2004.

MainWARING, S. Brazil: weak parties, feckless democracy. In: MAINWARING, S.; Scully, T. R. (eds.). Building democratic institutions: party systems in Latin America. Stanford: Stanford University Press, 1995. 
MANCINI, P.; SWANSON, D. Politics, media, and modern democracy: introduction. In: SWANSON, D. L.; MANCINI, P. (eds.). Politics, media, and modern democracy: an international study of innovations in electoral campaigning and their consequences. Westport: Praeger Publishers, 1996.

MANin, B. Los principios del gobierno representativo. Madrid: Alianza Editorial, 1998.

Maravall, J. M.; Przeworski, A. Political reactions to the economy: the Spanish experience. In: StOKes, S. C. (ed.). Public support for market reforms in new democracies. Cambridge: Cambridge University Press, 2001.

MARGolis, M.; MAUSER, G. A. Introduction: public opinion as a dependent variable. In: MARGolis, M.; MAUSER, G. A. (eds.). Manipulating public opinion. Pacific Grove: Brooks/Cole Publishing Company, 1989.

Masiero, G. Origens e desenvolvimento do populismo. In: Bresser Pereira, L. C. (org.). Populismo econômico. São Paulo: Nobel, 1991.

McDermott, R. "Experimental methods in political science". Annual Review of Political Science, vol. 5, p. 31-61, 2002.

Melo, C. R. "Partidos e migração partidária na Câmara dos Deputados". Dados, vol. 43, no 2, p. 207-223, 2000.

- Retirando as cadeiras do lugar: migração partidária na Câmara dos Deputados (19852002). Belo Horizonte: Editora UFMG, 2004.

Melo, C. R.; CÂMARA, R. "Estrutura da competição pela presidência e consolidação do sistema partidário no Brasil". Dados, Rio de Janeiro, vol. 55, no 1, p. 71-117, 2012.

Meneguello, R. "Electoral behavior in Brazil: the 1994 presidential elections". International Social Science Journal, vol. 147, no 47, p. 627-641, 1996.

MÉrola, V.; HitT, M. "Numeracy and the persuasive effect of policy information and party cues". Public Opinion Quarterly, vol. 80, no 2, p. 554-562, 2016.

MONTERO, J.; GUNTHER, R. Introduction: reviewing and reassessing parties. In: MONTERO, J.; GUNTHER, R.; LINZ, J. J. (eds.). Political parties: old concepts and new challenges. Oxford: Oxford University Press, 2002

Mundim, P. S. "Um modelo para medir os efeitos da cobertura da imprensa no voto: teste nas eleições de 2002 e 2006". Opinião Pública, vol. 16, no 2, p. 394-425, 2010.

Mundim, P. S.; Gramacho, W.; Pinto, A. J. P. "Razão e emoção: reações ao estado da economia e aprovação do governo federal". Opinião Pública, vol. 24, no 1, p. 90-113, 2018.

NAdeau, R., et al. "Economics and elections revisited". Comparative Political Studies, vol. 46, nº 5, p. 551-573, 2012.

NiCHOLSON, S.; HANSFORD, T. G. "Partisans in robes: party cues and public acceptance of supreme court decisions". American Journal of Political Science, vol. 58, no 3, p. 620-636, 2014.

NickelsbuRG, M.; NoRPOTH, H. "Commander-in-chief or chief economist? The president in the eye of the public". Electoral Studies, vol. 19, no 2-3, p. 313-332, 2000.

NicolaU, J. "Disciplina partidária e base parlamentar na Câmara dos Deputados no primeiro governo Fernando Henrique Cardoso (1995-1998)". Dados, Rio de Janeiro, vol. 43, no 4, p. 709-736, 2000. 
NoRRIS, P. Democratic phoenix: reinventing political activism. New York: Cambridge University Press, 2002.

O’DonNelL, G. "Delegative democracy?". Journal of Democracy, vol. 5, no 1, p. 55-69, 1992.

PAIVA, D.; TARouco, G. S. "Voto e identificação partidária: os partidos brasileiros e a preferência dos eleitores". Opinião Pública, Campinas, vol. 17, no 2, p. 426-451, nov. 2011.

Pereira, C.; Müeller, B. "Partidos fracos na arena eleitoral e partidos fortes na arena legislativa: a conexão eleitoral no Brasil". Dados, vol. 46, no 4, p. 735-771, 2003.

Peters, G. B. Comparative politics: theory and methods. New York: New York University Press, 1998.

Petersen, M. B., et al. "Motivated reasoning and political parties: evidence for increased processing in the face of party cues". Political Behavior, vol. 35, no 4, p. 831-854, 2012.

PRICE, V. Communication concepts 4: public opinion. Newbury Park: Sage Publications, 1992.

PrIOR, M. Post-broadcast democracy: how media choice increases inequality in political involvement and polarizes elections. Cambridge: Cambridge University Press, 2007.

POPKIN, S. The reasoning voter. Chicago: University of Chicago Press, 1991.

PoweLL, G. Elections as instruments of democracy: majoritarian and proportional visions. New Haven: Yale University Press, 2000.

RAY, L. "When parties matter: the conditional influence of party positions on voter opinion about European integration". Journal of Politics, vol. 65, no 4, p. 978-994, 2003.

RenNó, L.; Gramacho, W. "Let's blame everyone: executive and legislative evaluations of economic performance in Brazil and Chile". Journal of Politics in Latin America, vol. 2, p. 53-78, 2010.

Rennó, L.; Spanakos, A. P. "Fundamentos da economia, mercado financeiro e intenção de voto: as eleições presidenciais brasileiras de 1994, 1998 e 2002". Dados, vol. 49, no 1, p. 11-40, 2006.

Ribeiro, E.; CARreirÃo, Y.; Borba, J. "Sentimentos partidários e antipetismo: condicionantes e covariantes". Opinião Publica, Campinas, vol. 22, no 3, p. 603-637, dez. 2016.

RoBERTS, K. El neoliberalismo y la transformación del populismo en América Latina: el caso peruano. In: Mackinnon, M. M.; Petrone, M. A. (comps.). Populismo y neopopulismo en América Latina: el problema de la cenicienta. Buenos Aires: Eudeba, 1998.

RUESCHEMEYER, D. Can one or a few cases yield theoretical gains? In: MAHONEY, J.; RUESCHEMEYER, D. (eds.). Comparative historical analysis in social sciences. Cambridge: Cambridge University Press, 2003.

SAMUELS, D. "Determinantes do voto partidário em sistemas eleitorais centrados no candidato: evidências sobre o Brasil". Dados, vol. 40, no 3, p. 493-536, 1997.

SAMUELS, D.; ZUCCO JUNior, C. "The power of partisanship in Brazil: evidence from survey experiments". American Journal of Political Science, vol. 58, no 1, p. 212-225, 2014.

Frontmatter. In: SAMUels, D.; Zucco JUNIOR, C. Partisans, antipartisans, and nonpartisans: voting behavior in Brazil. Cambridge: Cambridge University Press, 2018.

SHIVELY, W. "The development of party identification among adults: exploration of a functional model". American Political Science Review, vol. 73, no 4, p. 1.039-1.054, 1979. 
Sniderman, P. The new look in public opinion research. In: FinifTer, A. W. (ed.). Political science: the state of the discipline II. Washington: The American Political Science Association, 1993.

SNIJDERS, T.; BOSKER, R. Multilevel analysis: an introduction to basic and advanced multilevel modeling. London: Sage Publications, 1999.

Steenbergen, M.; Jones, B. "Modeling multilevel data structures". American Journal of Political Science, vol. 46, no 1, p. 218-237, 2002.

Stokes, S. A defense of observational research. In: TeELE, D. (ed.). Field experiments and their critics. New Haven: Yale University Press, 2014.

StRøM, K.; SVÅSAND, L. (eds.). Challenges to political parties: the case of Norway. Ann Arbor: University of Michigan Press, 1997.

VREESE, C. "Political parties in dire straits? Consequences of national referendums for political parties". Party Politics, vol. 12, no 5, p. 581-598, 2006.

Weffort, F. O populismo na política brasileira. Rio de Janeiro: Paz e Terra, 1989.

WEYLAND, K. "Neopopulism and neoliberalism in Latin America: how much affinity?". Third World Quarterly, vol. 24, nº 6, p. 1.095-1.115, 2003.

ZALLER, J. The nature and origins of mass opinion. Cambridge: Cambridge University Press, 1992.

\begin{abstract}
Party cues in Brazil? A crucial test on the ability of the Brazilian party system to influence public opinion This article presents a crucial test for the theory of party cues by investigating the association between the legislative positions of the Brazilian political party system in a government-opposition dimension and the governmental assessment made by their supporters. The context of the test is the Fernando Henrique Cardoso government (1995-2002), characterized by successive economic crises, which would tend to reduce the parties' influence over public opinion, in face of the traditional explanatory power of theories of economic voting and VP-functions. The results, based on multilevel models built upon seven surveys, suggest that party cues work even in a country like Brazil and in the adverse context chosen for this empirical test. The findings also indicate that party cues were stronger according to the media relevance of each political party.
\end{abstract}

Keywords: party cues; government approval; media; economic voting; VP-functions; multilevel analysis

\title{
Resumen
}

¿Party cues en Brasil? Un test crucial de la capacidad del sistema de partidos brasileño para influir en la opinión pública

Este artículo presenta un test crucial de la teoría de las pistas partidistas al investigar la asociación entre las posiciones legislativas del sistema de partidos políticos brasileño en una dimensión gobiernooposición y la evaluación gubernamental realizada por sus simpatizantes. El contexto del test es el gobierno de Fernando Henrique Cardoso (1995-2002), marcado por sucesivas crisis económicas, que tenderían a reducir la influencia de los partidos sobre la opinión pública, frente al poder explicativo tradicional de las teorías del voto económico y de las funciones de popularidad. Los resultados de modelos multinivel basados en siete encuestas sugieren que las pistas partidistas funcionan incluso en un país como Brasil y en el contexto adverso elegido para esta prueba empírica. Los resultados también indican que las señales de los partidos eran más fuertes según la relevancia de cada partido en los medios de comunicación.

Palabras clave: pistas partidistas; aprobación gubernamental; medios de comunicación; voto económico; funciones de popularidad; análisis multinivel 


\section{Résumé}

Party cues au Brésil ? Un test crucial de la capacité du système des partis brésilien à influencer l'opinion publique

Cet article présente un test crucial pour la théorie des signaux des partis politiques en étudiant l'association entre les positions législatives du système des partis politiques brésiliens dans une dimension gouvernment-opposition et l'évaluation gouvernementale faite par leurs partisans. Le contexte du test est le gouvernement Fernando Henrique Cardoso (1995-2002), marqué par des crises économiques successives, qui tendraient à réduire l'influence des partis sur l'opinion publique, face au pouvoir explicatif traditionnel des théories du vote économique et des fonctions de popularité. Les résultats, basés sur des modèles à plusieurs niveaux construits sur sept enquêtes, suggèrent que les indices de parti fonctionnent même dans un pays comme le Brésil et dans le contexte défavorable choisi pour ce test empirique. Les résultats indiquent également que les indices des partis étaient plus forts selon la pertinence médiatique des partis.

Mots-clés: signaux des partis politiques; approbation du gouvernement; médias; vote économique; VP fonctions; analyse à plusieurs niveaux

Artigo submetido à publicação em 28 de fevereiro de 2020. Versão final aprovada em 18 de maio de 2021.

Opinião Pública adota a licença Creative Commons CC-BY. 